\title{
A Study for Allocating Resources in Research and Development Programs by Integrated Subjective and Objective Decision Method
}

\author{
Chun-Chu Liu \\ Department of International Business, Chang Jung Christian University, Taiwan, R.O.C
}

\begin{abstract}
A decision model is developed to help managers select the most appropriate sequences of plans for product Research and Development ( $\mathrm{R}$ and $\mathrm{D}$ ) projects that have strict constraints on budget, time, and resources. In recent years, many organizations have changed from a discipline orientation to a focus on integrated programs and related outcomes. For decision-maker of these high-profile $\mathrm{R}$ and D programs, it is critical to understand which activities are most important, considering both investment feasibility and cost-effectiveness. This study proposes a two-dimensional decision model that integrates analytic hierarchy process (subjective judgment method) and data envelopment analysis (objective judgment method) to perform this essential task. Based on information about these two decision science tools, the model develops a two-axis evaluation space for research alternatives. By locating particular activities in this decision space, a program manager can compare and prioritize alternative research investments.
\end{abstract}

Key words: Research and Development, Subjective Judgment Method, Objective Judgment Method

\section{INTRODUCTION}

A large corporation often faces a decision on the scope of product research and development ( $\mathrm{R}$ and $\mathrm{D})$ projects. The main criterion for evaluating such projects is that under the budget and timing constraints. Therefore, the selection of a balanced $\mathrm{R}$ and $\mathrm{D}$ portfolio, combining corporate goals, resources, and constraints, is an important but venturesome task ${ }^{[1]}$. Research portfolio analysis and decision models can be effective tools in promoting organizational participation in complex decision processes. This involvement develops a consensus for and understanding of organizational goals and the associated performance metrics. To achieve the goal, decision models should provide management information without the distraction of excessive complexity ${ }^{[2]}$. Specifically, models should provide benefits that exceed the difficulty and effort required for model development, use, and maintenance.

This study proposes integrating two complementary decision tools that have particular promise in R and D management environment: analytic hierarchy process (AHP) and data envelopment analysis (DEA). Major concerns in the two-dimensional decision model are compared, prioritize alternative research investments and the best allocation of the corporation's resources to selected projects.

An abundant literature exists for $\mathrm{R}$ and $\mathrm{D}$ project evaluation and selection, and it refers to hundreds of models using a wide range of mathematically based approaches ${ }^{[3-12]}$. Various researchers have provided a good review of these approaches to $\mathrm{R}$ and $\mathrm{D}$ project management. Very few have focused on examining the degree to which the techniques meet the requirements of the evaluation process ${ }^{[10]}$. According to Poth, etc. ${ }^{[10]}$ study results, which reveal weighting and ranking methods better than benefit-contribution methods. Several approaches have been proposed to determine weights ${ }^{[13,14]}$. Most Majorities of them can be classified as subjective and objective approaches depending on the information provided. The subjective approaches include the Analytic Hierarchy Process ${ }^{[14]}$, Delphi $\operatorname{method}^{[13]}$, and weighted least square method ${ }^{[15]}$ etc. The objective approaches include Date Envelopment Analysis $^{[16]}$, principal component analysis ${ }^{[17]}$, the entropy method ${ }^{[18]}$ and the multiple objective programming model ${ }^{[17]}$ etc. Subjective approaches determine weights that reflect subjective judgment, but those weights can be influenced by the DMUs. Objective approaches determine weights by making use of mathematical models, but they neglect subjective judgment.

This study combines both the subjective weight restriction method and the objective weight restriction method to evaluate investment alternatives based on the decision space shown in Fig. 1.

Two-dimensional Decision Model:

Subjective Weight Restriction Method: Several types of subjective weight restrict methods (such as Analytic Hierarchy Process, Delphi, and multiple criteria decision making) are currently used. These methods are characterized by the subjective setting of weights in the evaluation index, by experts, based on their own experience. Different scholars and experts may give different weights and thus, subjectivity is the major drawback. Remedial Measures such as increasing the numbers of experts, properly selecting experts, and so on, can diminish this drawback; however, subjectivity remains. 


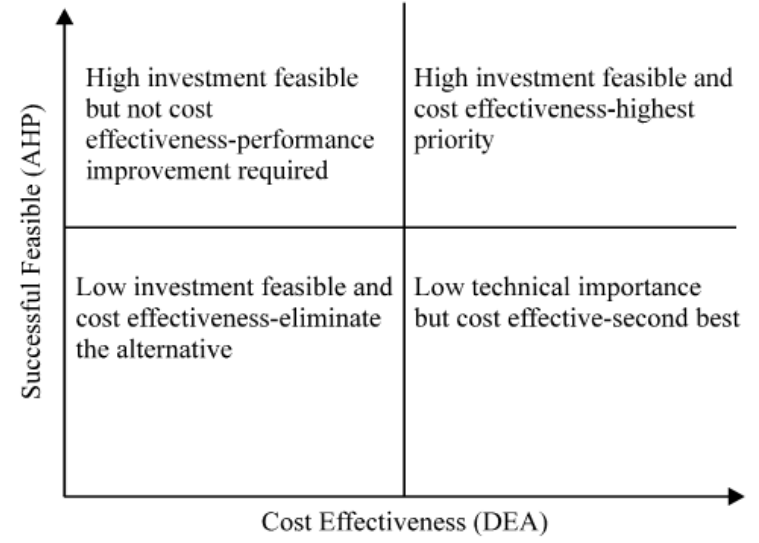

Fig. 1: Subjective and Objective Decision Space

Table 1: $\quad$ Ten R and D Activities Inputs and Outputs

\begin{tabular}{llcr}
\hline $\begin{array}{l}\text { R and D } \\
\text { alternatives }\end{array}$ & $\begin{array}{l}\text { Output } \\
\text { (\% complete) }\end{array}$ & $\begin{array}{l}\text { Inputs } \\
\text { Labor }\end{array}$ & Capital \\
\hline A1 & 100 & 1 & 200 \\
A2 & 100 & 2 & 250 \\
A3 & 100 & 3 & 225 \\
A4 & 100 & 4 & 125 \\
A5 & 100 & 5 & 150 \\
A6 & 100 & 6 & 150 \\
A7 & 100 & 7 & 120 \\
A8 & 100 & 8 & 80 \\
A9 & 100 & 9 & 100 \\
A10 & 100 & 10 & 40 \\
\hline
\end{tabular}

The advantage of the subjective weight restricts method is that experts can reasonably identify the weight index that corresponds to the actual problems. Thus, despite the different placement of weights in the index, the method can still determine the order of priority and avoid conflicts between the reality and the index weights, as can occur in the objective weight restrict method. This study uses AHP, which process is described as follows.

Thomas L. Saaty first proposed the Analytic Hierarchy Process in 1971, and over the past few decades, due to the research efforts of Saaty et al., an AHP can now be categorized as one of 31 types $^{[19]}$. Now, AHP is considered to be an efficient management tool for modern enterprises.

The strongest function of AHP is to simplify a complicated system into a hierarchy of processes, each including simple but essential elements. In short, the procedure affects the incentives of each decision making point and the pairwise comparisons between the nominal scales. After the process of quantifying, a comparison matrix is established to obtain the Eigenvector, representing the weight of each hierarchy, and the eigenvalue. From the above, the corresponding strength and weakness of the individual pairwise comparison used as information for decision-making. In addition, if the factors of AHP are interrelated in many hierarchies, the priority and then the connection are determined to obtain the combined weight of factors in the lower hierarchy. Combining the consistency indices in all the comparison matrices provides each consistency index and ratio to evaluate on the common recognition of the entire hierarchy.

Objective Weight Restriction Method: Researchers have been working on objective weight restriction method (DEA, Gray prediction, Composition analysis) to avoid the shortcomings of the subjective weight restriction method. The primary data of the objective weight restrict method are the actual figures used in the matrix for evaluation to avoid subjective sources and ensure the weights are objectively given. Yet, sometimes, inevitably the subjective weight may correspond to fact. The least important index could theoretically have the largest weighting and the most important index may not be the case. Examples can be seen in many DEA analyses.

Accordingly, the subjective weight restriction method has its advantages, and the objective method also has some advantages if the practical situation is neglected. In the real situation, where weights are obtained through either the subjective or the objective method, the difference between the methods tends to be ignored and, therefore, their reliability becomes doubtful.

This study concentrates on the advantage of the integration and objectification of the weight restriction method to offer more reliable information for decision-making.

Example: First, to clearly illustrate the DEA concept, percentage completion is the only output, and each $\mathrm{R}$ and $\mathrm{D}$ activity is assessed on the input resources (here are labor and capital) required to achieve 100\% completion. Table 1 presents a summary of the inputs and outputs for the ten R and D activities.

Since a uniform output has been selected and two inputs are used in the example, an easily interpreted graphical representation can be developed to provide insight into the DEA results. Figure 2 plots the input data for the $\mathrm{R}$ and $\mathrm{D}$ alternatives and shows that the productivity frontier is composed of alternatives one, four, and ten. Alternatives two, three, five, six, seven, eight and nine are not as efficient and are beyond the frontier.

Second, applying AHP for evaluation successful feasible for R and D investment alternatives. Figure 3 shows the AHP hierarchy for our investment alternatives. Our objective is to perform a comparative study of the ten investment alternatives. These ten investment alternatives are enumerated at level 3 of the hierarchy in Fig. 3. 


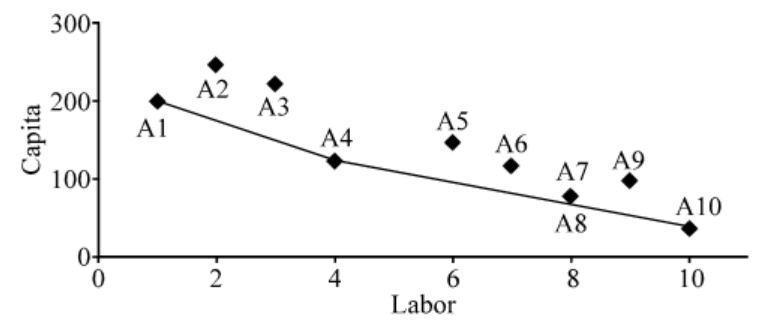

Fig. 2: Ten Alternative's Productivity Frontier

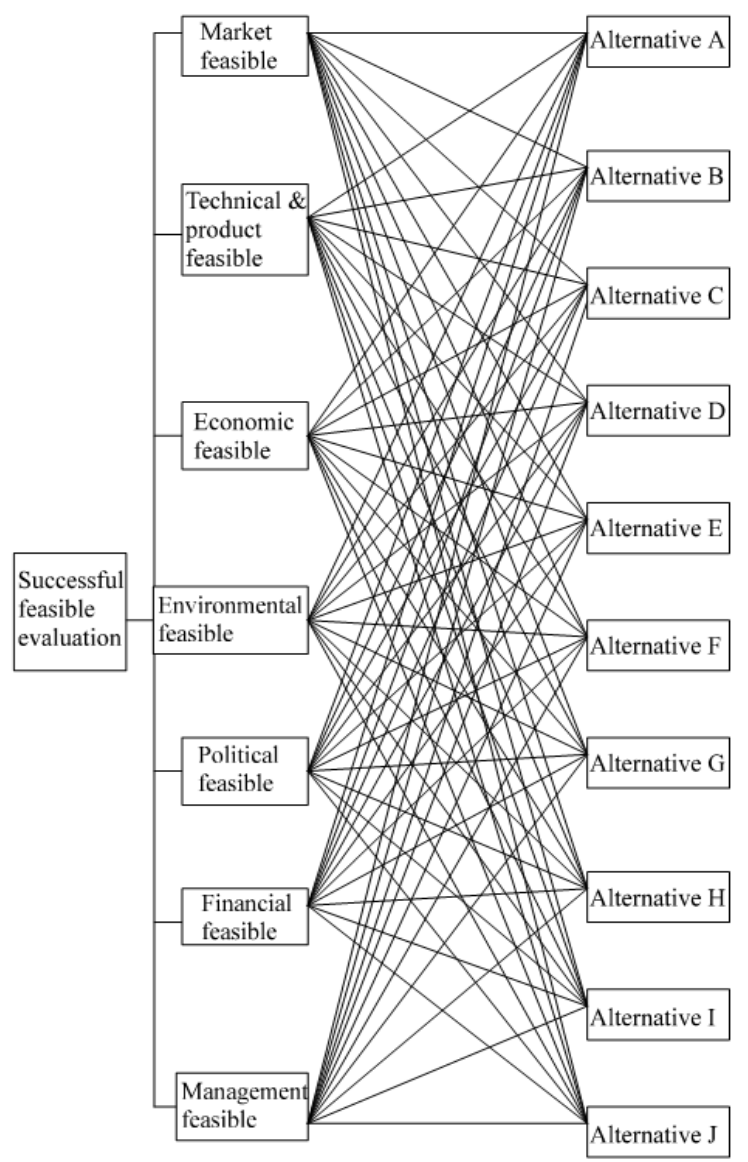

Fig. 3: AHP Hierarchies for Successful Feasible Evaluation

Table 2: Summary of DEA and AHP Values

\begin{tabular}{lcc}
\hline $\begin{array}{l}\text { R and D } \\
\text { Alternatives }\end{array}$ & $\begin{array}{l}\text { Successful } \\
\text { feasible from } \\
\text { AHP method }\end{array}$ & $\begin{array}{l}\text { Cost effectiveness } \\
\text { from DEA method }\end{array}$ \\
\hline A1 & 0.073 & 1.00000 \\
A2 & 0.09 & 0.75 \\
A3 & 0.11 & 0.75 \\
A4 & 0.08 & 1.00000 \\
A5 & 0.16 & 0.82264 \\
A6 & 0.109 & 0.77305 \\
A7 & 0.075 & 0.82890 \\
A8 & 0.094 & 0.93966 \\
A9 & 0.089 & 0.79853 \\
A10 & 0.12 & 1.00000 \\
\hline
\end{tabular}

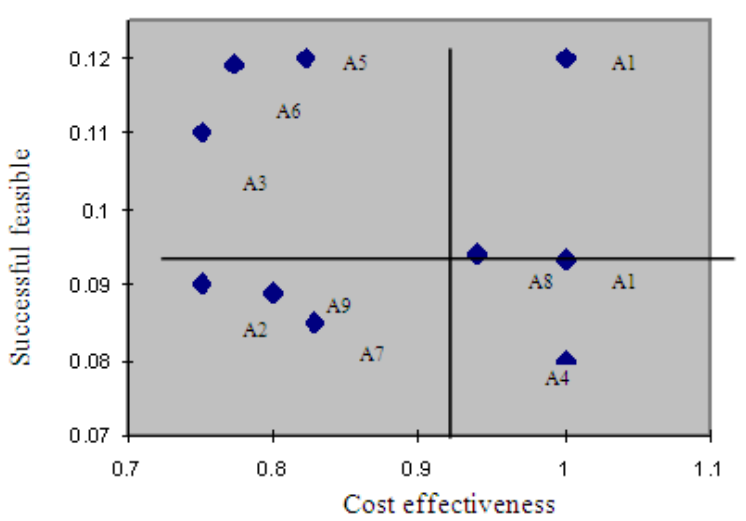

Fig. 4: Two-Dimensional Decision Space

At the highest level of the hierarchy, we specify the goal, which is the identification of the successful feasible for R and D investment alternatives. Level 2 of the hierarchy lists seven major criteria that critical in determining the effectiveness of $\mathrm{R}$ and $\mathrm{D}$ investment alternatives. Level 3 of the hierarchy lists ten investment alternatives.

To provide the DEA and AHP solution for this example, IDEAS 5.0 and Expert choice 2000 solved those results are summarized in Table 2, along with a theoretical set of AHP successful feasible ratings. The $\mathrm{R}$ and $\mathrm{D}$ alternatives value for both the AHP-developed successful feasible ratings and the DEA objective function values are plotted in Fig. 3. Based on the four-quadrant analysis, the decision maker can draw the following conclusions:

$\mathrm{R}$ and $\mathrm{D}$ alternatives ten is both productive and successful feasible. These are very high-priority programs.

$\mathrm{R}$ and $\mathrm{D}$ alternatives one, four and eight are productive but not successful feasible. As a result, this program is a low priority for funding.

$\mathrm{R}$ and $\mathrm{D}$ alternatives five, seven and nine should be eliminated. They are not productive and not important.

$\mathrm{R}$ and $\mathrm{D}$ alternatives three and six should be targeted for improvement if possible. It is an important program but not cost-effective compared to other programs.

\section{CONCLUSION}

This study introduces a two-dimensional decision model, a planning and scheduling tool that helps decision-maker evaluate and analyze schedules and resource requirements for $\mathrm{R}$ and $\mathrm{D}$. By building on the strengths of two simple, yet powerful, decision tools, the model employs AHP and DEA to develop a decision space that identifies critical impact areas for decision makers. Using AHP, the model identifies the activities that are successful feasible to achieve organizing goals. DEA identifies the activities that are cost-effective and thereby brings the reality of limited 
budgetary resources into the decision process. Together, these two data elements allow the decision maker to evaluate and compare research alternatives in a two-dimensional space. Specially, the two-dimensional model incorporates the following features:

An additional benefit of this model is that it reduces subjective judgment.

A scientific and systematic product development process to help managers choose the "right" project.

A resource allocation plan to help managers perform the development process "right."

The flexibility of this model makes possible a wide range of application opportunities.

\section{ACKNOWLEDGMENT}

The author would like to thank the National Science Council of the Republic of China for financially supporting this research under Contract No. NSC90-2146-H-309-009-.

\section{REFERENCES}

1. Islei, G., G. Lockett, B. Cox, and M. Stratford, 1991. A decision support system using judgment modeling: A case of $\mathrm{R}$ and $\mathrm{D}$ in the pharmaceutical industry. IEEE Trans. On Engineering Management, EM-38: 202-209.

2. Howard, Ronald A., 1988. Decision analysis: Practice and Promise. Manage. Sci., 34: 679-695.

3. Baker, N.R. and W.H. Pound, 1964. R and D project selection: Where do we stand? IEEE Trans. On Engineering Management, EM-21: 124-134.

4. Schroder, H., 1971. R and D project evaluation and selection models for development: A survey of the state of the ART. Socio-Econ. Plan. Sci., 5: 25-39.

5. Baker, N.R. and J.R. Freeland, 1971. Recent advantages in $\mathrm{R}$ and $\mathrm{D}$ benefit measurement and project selection methods. Manage. Sci., 21: 1164-1175.

6. Albala, A., 1975. Stage approach for the evaluation and selection of $\mathrm{R}$ and $\mathrm{D}$ projects. IEEE Trans. On Engineering Management, EM-22: 153-164.

7. Liberatore, M.L., and G.J. Titus, 1986. Managing the industrial $\mathrm{R}$ and $\mathrm{D}$ project: Current practice and future direction. J. Social Res. Administ., 18: 5-12.
8. Souder, William E., and Tomislav Mandakovic, 1986. R and D project selection models. Res. Manag., 29: 36-42.

9. Roussell, Philip A., Kamal N. Saad, and Tamara J. Erickson, 1991. Third Generation $\mathrm{R}$ and D: Managing the Link to Corporate Strategy. Harvard Business School Press.

10. Poth, K.L., B.W. Ang and F. Bai, 2001. A comparative analysis of $\mathrm{R}$ and $\mathrm{D}$ project evaluation methods. R and D Management, 31: 63-75.

11. Osawa, Yoshitaka and Michikazu Murakami, 2002. Development and application of a new methodology of evaluating industrial $R$ and $D$ projects. R and D Management, 32: 79-86.

12. Meade, L.M. and A. Presley, 2002. R and D project selection using the analytic network process. IEEE Trans. On Engineering Management.

13. Hwang, C.L. and M.J. Lin, 1987. Group decision making under multiple criteria: Method and Application. Spring Berlin.

14. Saaty, T.L., 1980. A scaling method for priorities in hierarchical structures. J. Math. Psychol., 15: 234-281.

15. Chu, A.T.W., R.E. Kalaba and K. Spingarn, 1979. A comparison of two methods for determining the weights of belonging to fuzzy sets. J. Optimization Theory and Application, 27: 531-538.

16. Charnes, A., W.W. Cooper and E. Rhodes, 1978. Measuring the efficiency of decision making units. European J. Oper. Res., 12: 429-444.

17. Fan, Z.P., 1996. Complicated multiple attribute decision making: Theory and applications. Ph.D. Thesis. Northwestern University, Shenyang, PRC.

18. Hwang, C.L. and K. Yoon, 1981. Multiple Attribute Decision Making: Methods and Applications. Springer, Berlin.

19. Smith J.P., 1989. Bibliographical Research on the Analytic Hierarchy Process (AHP). Socio-Econ. Plan. Sci., 23: 161-167. 